\title{
Relations between vital capacity, CO diffusion capacity and computed tomographic findings of former asbestos- exposed patients: a cross-sectional study
}

\author{
Alexandra Marita Preisser ${ }^{1 *}$ (D, Katja Schlemmer ${ }^{1}$, Robert Herold ${ }^{1}$, Azien Laqmani ${ }^{2}$, Claudia Terschüren ${ }^{1}$ and
} Volker Harth ${ }^{1}$

\begin{abstract}
Background: Asbestos-related lung diseases are one of the leading diagnoses of the recognized occupational diseases in Germany, both in terms of their number and their socio-economic costs. The aim of this study was to determine whether pulmonary function testing (spirometry and CO diffusion measurement $\left(\mathrm{D}_{L \mathrm{LCO}}\right)$ ) and computed tomography of the thorax (TCT) are relevant for the early detection of asbestos-related pleural and pulmonary fibrosis and the assessment of the functional deficiency.

Methods: The records of 111 formerly asbestos-exposed workers who had been examined at the Institute for Occupational and Maritime Medicine, Hamburg, Germany, with data on spirometry, DLco and TCT were reviewed. Workers with substantial comorbidities (cardiac, malignant, silicosis) and/or pulmonary emphysema (pulmonary hyperinflation and/or TCT findings), which, like asbestosis, can lead to a diffusion disorder were excluded. The remaining data of 41 male workers (mean 69.8 years \pm 6.9 ) were evaluated. The TCT changes were coded according to the International Classification of High-resolution Computed Tomography for Occupational and Environmental Respiratory Diseases (ICOERD) by radiologists and ICOERD-scores for pleural and pulmonary changes were determined. Correlations $(\rho)$, Cohens $k$ and accuracy were calculated.

Results: In all 41 males the vital capacity (VC in \% of the predicted value (\% pred.)) showed only minor limitations (mean $96.5 \pm 18.0 \%$ ). The $D_{L c o}$ (in \% pred.) was slightly reduced (mean $76.4 \pm 16.6 \%$; median $80.1 \%$ ); the alveolar volume related value ( $D_{\text {LCO NA) }}$ was within reference value (mean $102 \pm 22 \%$ ). In the TCT of 27 workers pleural asbestos-related findings were diagnosed whereof 24 were classified as pulmonary fibrosis (only one case with honey-combing). Statistical analysis provided low correlations of VC $(\rho=-0.12)$ and moderate correlations of $D_{L C O}(-0.25)$ with pleural plaque extension. The ICOERD-score for pulmonary fibrosis correlated low with VC $(0.10)$ and moderate with $D_{L C O}(-0.23)$; $D_{L C O}$ had the highest accuracy with 73.2\% and Cohens $k$ with 0.45. DLCONA showed no correlations to the ICOERD-score. The newly developed score, which takes into account the diffuse pleural thickening, shows a moderate correlation with the $D_{L C O}(\rho=-0.35, p<0.05)$.

(Continued on next page)
\end{abstract}

\footnotetext{
* Correspondence: a.preisser@uke.de

'Institute for Occupational and Maritime Medicine (ZfAM), University Medical Center Hamburg-Eppendorf (UKE), Hamburg, Germany

Full list of author information is available at the end of the article
}

\section{$\triangle B M C$}

(c) The Author(s). 2020 Open Access This article is licensed under a Creative Commons Attribution 4.0 International License, which permits use, sharing, adaptation, distribution and reproduction in any medium or format, as long as you give appropriate credit to the original author(s) and the source, provide a link to the Creative Commons licence, and indicate if changes were made. The images or other third party material in this article are included in the article's Creative Commons licence, unless indicated otherwise in a credit line to the material. If material is not included in the article's Creative Commons licence and your intended use is not permitted by statutory regulation or exceeds the permitted use, you will need to obtain permission directly from the copyright holder. To view a copy of this licence, visit http://creativecommons.org/licenses/by/4.0/ The Creative Commons Public Domain Dedication waiver (http://creativecommons.org/publicdomain/zero/1.0/) applies to the data made available in this article, unless otherwise stated in a credit line to the data. 


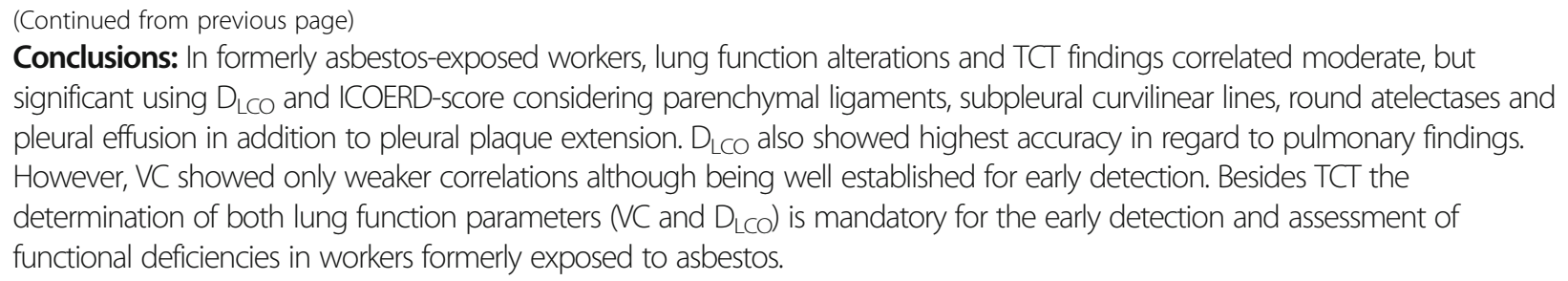

Keywords: Asbestosis, Pleural plaques, Lung function, CO diffusion capacity, Vital capacity, Parenchymal bands, Subpleural curvilinear lines, Round atelectasis, Thorax computed tomography, ICOERD

\section{Background}

Occupational diseases due to asbestos exposure are the fourth most confirmed occupational disease in Germany in 2018 with 3401 cases [1]. In 2018, 65\% of all deaths due to an occupational disease were caused by asbestos [2]. As a result of the widespread use of the building material asbestos and the long latency between exposure and first symptoms, a considerable number of unreported cases must be assumed. About 40\% ( $€ 250$ million) of the health care costs and compensatory payments covered by the German Social Accident Insurance are attributed to occupational diseases caused by asbestos [3].

In addition to malignant diseases (which are not discussed here), the consequences of exposure to asbestos are typical pleural plaques, pleuritis and pulmonary fibrosis (asbestosis) with the consequence of a restrictive ventilation disorder. Restrictive lung diseases show a reduction of all lung volumes at normal relative one-second capacity $\left(\mathrm{FEV}_{1} / \mathrm{FVC}\right)$ and a gas exchange disorder with decrease of the diffusion capacity for carbon monoxide ( $\mathrm{D}_{\mathrm{LCO}}$ and $\left.\mathrm{D}_{\mathrm{LCO}} / \mathrm{VA}\right)$.

The pathognomonic changes of the pleura and the typical changes of the lung parenchyma caused by asbestos are better identifiable on TCT than on chest X-ray [4]. The lung parenchyma signs include a centrilobular increase in density, intralobular structures that are not ordered in septa, and thickened interlobular septa. Subpleural curvilinear lines (SC) running parallel to the thoracic wall indicate the onset of fibrosis. Socalled parenchymal bands (PB) are visible in TCT as pleuropulmonary fibrotic strands. Honeycombing is the term for maximum fibrosis, i.e. the destruction of the lung parenchyma [5-9]. Asbestosis is difficult to detect in early stages $[9,10]$.

So far, there are different views on the effect of plaques on lung function: Some studies show that a deterioration of lung function, e.g. as a restriction of vital capacity $(\mathrm{VC})$ and forced expiratory vital capacity over $1 \mathrm{~s}\left(\mathrm{FEV}_{1}\right)$, can be detected in patients with proven exposure to asbestos and pulmonary fibrosis in X-ray or CT scans [1113]; only a few publications also consider $\mathrm{CO}$ diffusion capacity $\left(D_{\mathrm{LCO}}\right)$ [14-16]. According to our own studies, limitations in diffusion capacity are the most sensitive parameter for determining a disease with an asbestosrelated cause [17]. Even though there is evidence in the studies mentioned above, it is still unclear whether lung function restrictions are in fact present, if, besides pleuroparietal plaques, no or only minimal changes (like SC or $\mathrm{PB}$ ) caused by asbestos are visible in the $\mathrm{CT}$, or whether structural alterations of the lung parenchyma are mandatory for lung function impairments. By this, secondary prevention measures for the detection and confirmation of compensatory payments should be initiated at an early stage. Non-invasive, low-radiation and economically appropriate methods like lung function test should be available for this purpose. So, the aim of this study was to determine whether pulmonary function testing (spirometry and $\mathrm{D}_{\mathrm{LCO}}$ ) and computed tomography of the thorax (TCT) are relevant for the early detection of asbestos-related pleural and pulmonary fibrosis and the assessment of the functional deficiency.

\section{Methods}

The study was conducted retrospectively with data from patient records of 111 occupationally asbestos-exposed workers and was obtained by experts from the Institute for Occupational and Maritime Medicine (ZfAM), Hamburg (Germany), between January 2013 and October 2016 for clarification/confirmation or follow-up of an asbestosrelated disease. In addition to TCT and medical history, following parameters of lung function were gathered: $\mathrm{VC}$ measurement $\left(\mathrm{VC}_{\max }, \mathrm{FVC}\right), \mathrm{CO}$ diffusion capacity $\left(\mathrm{D}_{\mathrm{LCO}}\right.$, and $\left.\mathrm{D}_{\mathrm{LCO}} / \mathrm{VA}\right)$, spirometry $\left(\mathrm{FEV}_{1} / \mathrm{FVC}\right)$, body plethysmography, and if necessary bronchospasmolysis test to determine non-reversible pulmonary hyperinflation. Furthermore, haemoglobin value and percent of $\mathrm{CO}$ haemoglobin were determined. The medical history was screened for other diseases that restrict lung function and pulmonary gas exchange to exclude patients with e.g. lung cancer, silicosis, sarcoidosis or hypersensitivity pneumonitis as well as cardiac diseases. Moreover, patients with pulmonary emphysema were not included in the study, as reduced diffusion capacity may be the result of both asbestosis and emphysema. For the diagnosis of pulmonary emphysema, shown by 15 patients, at least one of the following criteria had to be met: (1) Increase of residual volume (RV) and ratio of residual volume to total lung 
capacity (RV/TLC > upper limit of normal (ULN)), not reversible after bronchospasmolysis [18]. (2) "Emphysema kink" in the flow-volume curve [19], (3) Radiological findings of an emphysema.

Finally, 41 male subjects met the quality criteria of completeness and comparability of the examination and assessment methods. Information on age, height and weight, duration of previous exposure to asbestos and smoking behaviour (former or active smoker; number of packyears (py)) were included. Every person who is examined in our outpatient clinic (ZfAM) gives their written consent that we may conduct further studies with their anonymized data and write publications about. According to the Ethics Committee of the Hamburg Medical Association an extra ethics vote is not necessary due to in-house research and retrospective evaluation of the data.

\section{Spirometry, body plethysmography and CO diffusion capacity}

Spirometry and body plethysmography had been carried out according to the quality criteria of the European Respiratory Society (ERS) [20], the American Thoracic Society (ATS) [21] and German Guideline for standardization of spirometry [22], demanding three artefact-free spirometry breathing manoeuvres. Following the guidelines, the higher result of two reproducible manoeuvres was selected. For the interpretation of lung function, the reference values for spirometry of the Global Lung Initiative (GLI) [23] and for body plethysmography of the European Coal and Steel Community (ECSC) [24] were used. $\mathrm{D}_{\mathrm{LCO}}$ was performed in single breath (SB) method according to the recommendations of MacIntyre et al. [25] and Graham et al. [26] using the predicted values by Cotes et al. [27]. If the haemoglobin $(\mathrm{Hb})$ value was determined, the $\mathrm{D}_{\mathrm{LCO}}$ values were adjusted (corr. $\mathrm{D}_{\mathrm{LCO}}=$ $\mathrm{D}_{\mathrm{LCO}}{ }^{*}(10.22+\mathrm{Hb}) /\left(1.7^{*} \mathrm{Hb}\right)$ according to Mottram et al. [28]. This adjustment was performed in 22 of 41 cases; in cases where there was no clinical evidence of anemia and the $\mathrm{Hb}$ value was missing, an $\mathrm{Hb}$ value of $14.6 \mathrm{~g} / \mathrm{dl}$ was assumed. All statistical analyses were performed with corr. $\mathrm{D}_{\mathrm{LCO}}$ values calculated to a normal $\mathrm{Hb}$ value.

\section{Computed tomography of the lung}

To ensure a standardised evaluation, the International Classification of Occupational and Environmental Respiratory Disease (ICOERD) was used to assess the TCTs $[29,30]$. The semi-quantitative description and coding were performed by radiologists following the guidelines for assessment and image data documentation by Hering et al. [8]. In 32 (78\%) of the subjects, TCT was performed with a maximum interval of 30 days after/before administering the lung function test; in five subjects within 31 to 180 days and in four subjects within 181 to 365 days (mean 42 days, SD 82).

\section{The coding scheme of the international classification of occupational and environmental respiratory diseases (ICOERD)}

The ICOERD coding scheme is regarded as the current standard for the diagnosis of computed tomographic image material in pneumoconiosis [29]. In the section "Lung" the International Classification indicates irregular and/or linear compression and honey-combing. In the "Pleura" section, two forms of pleural changes can be differentiated: the parietal type with tableland-shaped or flat, partly spindle-shaped thickenings of the pleura without subpleural fibrosis and the visceral type with thickenings of the pleura with adjacent parenchymal ligaments. The parietal type can be regarded as highly asbestos-related pleural plaques, while the visceral type can be caused differently [8]. According to the Helsinki criteria, the minimum requirement for a clear diagnosis of asbestosis in the TCT is fibrosis, which is represented by at least two bilateral irregular densifications of the lower lung sections and/or bilateral honeycombing with a total of more than 2 points $[10,31]$.

\section{Scores}

ICOERD is used to assign scores to various structures, some of which are used as the basis for this evaluation. Score A quantifies the pleural plaques and thus reflects their local extent; according to the occurrence at the right $(\mathrm{R})$ and left $(\mathrm{L})$ pleura and there depending on the proportion with $\mathrm{U}, \mathrm{M}$ and $\mathrm{L}$ (for upper, middle and lower field, respectively $\mathrm{R}$ and L) [5]. This score ranges between 0 and 6 points and mainly takes into account plaques of the parietal type. Score $B$ for the occurrence of fibrosis of the lung parenchyma is derived from the ICOERD according to the total variance of irregular and/or linear opacities. The score/point value for pulmonary fibrosis can range from 0 to 18 points.

In addition to these scores $A$ and $B$ a newly developed combined pleural score is tested. Besides the extent of parietal pleural plaques, typical alterations such as visceral pleural thickening are also considered. These diffuse pleural thickenings are taken into account in this new score by additional point values for 'parenchymal bands' (PB), 'round atelectases' (RA), 'subpleural curvilinear lines' (SC) and 'effusion, free or loculated pleural fluid' (EF). The point value from the distribution of pleural plaques ( $0-6$ points), as described above, is now multiplied by the score value from $1+\mathrm{PB}+\mathrm{RA}+\mathrm{SC}+$ $\mathrm{EF}$, i.e. $1-5$ points. This combined score thus allows a value of $0-30$. Figure 1 depicts the score calculation for a representative study subject.

Further ICOERD-based scores were tested weighting differently the pleural and pulmonary extensions and additional findings; e.g. a score adding additional points for calcification and the additional attributes PB and RA, 


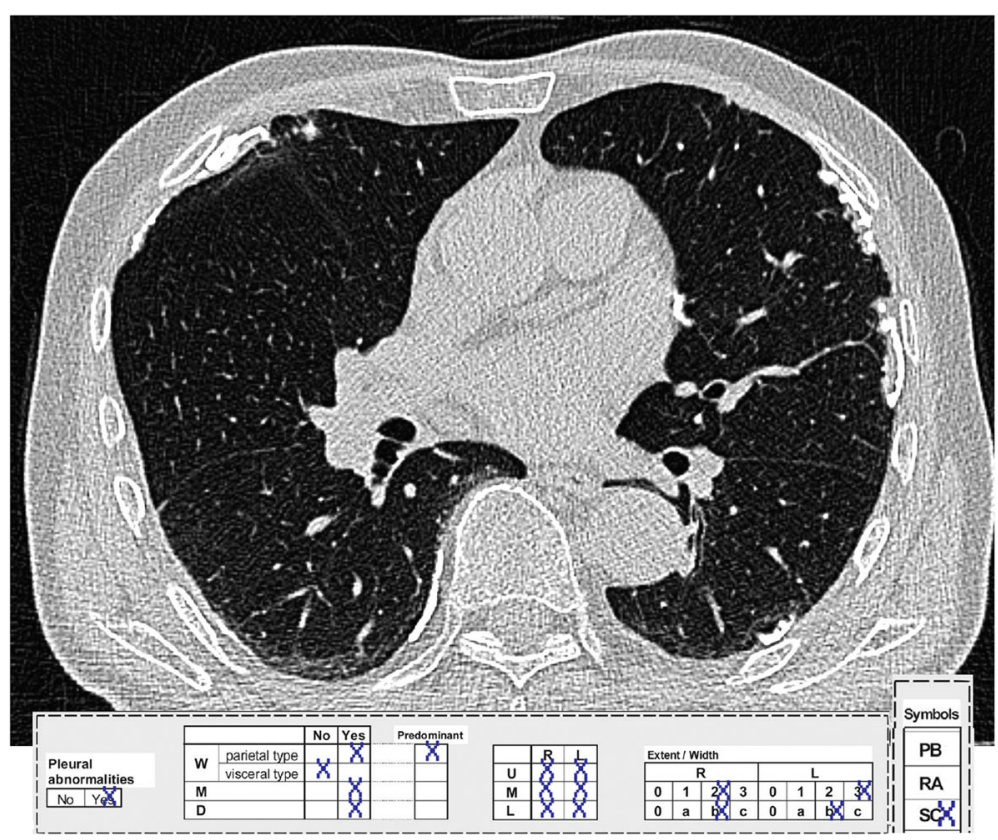

Fig. 1 Findings and calculation of score values for pleura plaques and subpleural curvilinear lines in a representative patient: 6 points (for the distribution of pleural plaques) multiplied with 2 points (value from $1+P B+R A+S C+E F)=12$

a score from the addition of the pleural point values (16 ) and the mentioned extra points with the pulmonary point values (1-18), and a score as addition of the above mentioned score with the score of the parenchymal fibrosis. Since these scores could not demonstrate sufficient predictive value or specificity, the score systems were not presented here.

\section{Statistical analysis}

ICOERD-scores indicating the presence of pleural plaques (corresponding to the above-mentioned score value 0-6) and the lung function parameters vital capacity (VC), diffusion capacity $\mathrm{D}_{\mathrm{LCO}}$, and transfer coefficient $\mathrm{D}_{\mathrm{LCO}} / \mathrm{VA}$ (also called $\mathrm{KCO}$ ) were included for testing statistical correlation. The lung function parameters were fitted into statistical model in \% of the predicted value to compensate for deviations in absolute values due to differences in body size and age [27]. VC, $\mathrm{D}_{\mathrm{LCO}}$ and $\mathrm{D}_{\mathrm{LCO}} / \mathrm{VA}$ as well as the scores of the pleural plaques (score $A$ ), the parenchymal fibrosis (score B) and the score for pleural plaques with visceral involvement (combined score) were tested for correlation.

Since the study group is consisting of less than 50 subjects, the Shapiro-Wilk test was performed to test for normal distribution within the individual groups. The correlation coefficient (Spearmans rho, $\rho$ ) and statistical significance were determined to measure the direction and strength of a possible linear relationship between the individual parameters of spirometry, diffusion capacity and CT findings. An ANOVA variance analysis was performed to compare the differently classified groups with each other. Further analyses were carried out using four-field matrix. Therefore individuals were classified as 'healthy' or 'sick' by exceeding or undercutting the lower limit of normal (LLN) for the respective lung function parameter tested and by the presence of pleural plaques or parenchymal fibrosis in the TCT. The latter is present when at least an ICOERD-score of 2 is reached [5]. Accuracy and Cohens Kappa were calculated.

The program " $R$ " (version 3.5.0) was used for the statistical analyses. Participants gave written (informed) consent to clinical studies.

\section{Results}

The exclusively male patient collective was fairly homogeneous with regard to age, height, weight, BMI and haemoglobin content of the blood ( $\mathrm{Hb}$ ) (Table 1). Of the 41 patients, 10 (24\%) reported continuing active smoking, 22 (54\%) were former smokers, 9 (22\%) had never smoked. The smokers had a cigarette consumption of 25.6 pack years (py) $(S D \pm 20.8)$. The exposure duration (in years) to dusts containing asbestos was also determined. There were no statistical correlations to the changes in lung function values. This aspect will therefore not be pursued further.

\section{Spirometry, whole body plethysmography, diffusion capacity $\left(D_{\text {LCO }}\right)$ and transfer coefficient $\left(D_{\text {LCO }} / \mathrm{VA}\right)$, and the ICOERD}

Table 2 shows the homogeneous distribution for the measured values from spirometry, whole body plethysmography 
Table 1 Demographic data of the patients $(n=41)$

\begin{tabular}{lccc}
\hline Variable & Mean & SD & Median \\
\hline age [years] & 69.8 & 6.9 & 72 \\
height [cm] & 174.7 & 6.4 & 176 \\
weight $[\mathrm{kg}]$ & 88.9 & 15.2 & 88 \\
$\mathrm{BMI}\left[\mathrm{kg} / \mathrm{m}^{2}\right]$ & 29.1 & 4.5 & 29.4 \\
Cigarette smoking [py] & 25.6 & 20.8 & 30 \\
$\mathrm{Hb}[\mathrm{g} / \mathrm{dL}]$ & 14.6 & 1.5 & 14.6 \\
\hline
\end{tabular}

$S D$ standard deviation, $p y$ pack years, $H b$ haemoglobin

and $\mathrm{CO}$ diffusion capacity. The VC shows slight limitations compared to the predicted value (mean $96.47 \% \pm 17.96$ ). The $\mathrm{D}_{\mathrm{LCO}}$ is also reduced compared to the predicted value (mean $76.35 \% \pm 16.58)$ while $\mathrm{D}_{\mathrm{LCO}} / \mathrm{VA}$ shows minor deviation from the reference value (mean $102.29 \% \pm 21.88$ ).

Finally, according to the TCT $27(66 \%)$ of the 41 patients were diagnosed with parietal-type pleural plaques; six (15\%) patients showed additional or isolated diffuse pleural thickening; 22 had calcifications in the plaques. The high prevalence of parietal pleural plaques in the study population is caused by and typical for occupational-related asbestos exposures [8]. The score for the localization of the parietal plaques (score A) are predominantly 2 points with $n=10$, only a few have 3 points $(n=3)$ and 4 points $(n=4)$. One patient achieves only one point or the maximum value of 6 points. Additional points for diffuse pleural thickening were given for $\mathrm{PB}$ in 14 cases, RA in 2, SC in 8, and EF in 2 cases. Further symbol markings, as specified in the ICOERD, serve to identify comorbidities and were only taken into account in this evaluation if they indicated the presence of exclusion criteria, e.g. heart disease. Eighteen patients

Table 2 Results of spirometry, body plethysmography, $D_{L C O}$ and DLCONA $(n=41)$

\begin{tabular}{|c|c|c|c|c|}
\hline Variable & Mean & SD & Median & \%pred. \\
\hline $\bar{V} C_{\max }[\mathrm{L}]$ & 3.93 & 0.89 & 4.00 & 96.47 \\
\hline FVC [L] & 3.91 & 0.91 & 3.93 & 95.15 \\
\hline $\mathrm{FEV}_{1}[\mathrm{~L}]$ & 2.84 & 0.79 & 2.78 & 90.90 \\
\hline $\mathrm{sR}\left[\mathrm{kPa}^{*} \mathrm{~s}\right]$ & 0.71 & 0.43 & 0.62 & 80.80 \\
\hline $\mathrm{RV}[\mathrm{L}]$ & 2.75 & 0.64 & 2.67 & 105.70 \\
\hline TLC [L] & 6.68 & 1.16 & 6.57 & 96.95 \\
\hline RV/TLC [\%] & 41.35 & 7.59 & 39.64 & 100.38 \\
\hline $\mathrm{D}_{\mathrm{LCO}}\left[\mathrm{mmol}^{*} \mathrm{~min}^{-1 *} \mathrm{kPa}^{-1}\right]$ & 6.66 & 1.48 & 6.93 & 76.35 \\
\hline $\mathrm{D}_{\mathrm{LCO}} \mathrm{NA}\left[\mathrm{mmol}^{*} \mathrm{~min}^{-1 *} \mathrm{kPa}^{-1}\right]$ & 1.30 & 0.26 & 1.30 & 102.29 \\
\hline VIN [L] & 3.64 & 0.89 & 3.64 & 86.68 \\
\hline
\end{tabular}

$V C_{\max }$ maximum vital capacity, $F V C$ forced expiratory vital capacity, $F E V_{1}$ expiratory one-second capacity, $s R$ specific resistance, $R V$ residual volume, $T L C$ total lung capacity, $R V / T L C$ share of residual volume in total lung capacity. $D_{L C O}$ haemoglobin value $(\mathrm{Hb})$ corrected diffusion capacity with $C \mathrm{C}, D_{L C O}, V_{A} \mathrm{Hb}$ corrected diffusion capacity with $\mathrm{CO}$ relative to alveolar volume, VIN inspiratory volume, SD standard deviation, \%pred. \% of predicted value show pulmonary fibrosis, only one patient honey combing.

Figures 2, 3, 4 and 5 show the distributions of the score $B$ for parenchymal changes and the newly formed combined score for parietal pleural plaque expansion and diffuse pleural thickening, taking into account $\mathrm{PB}$, $\mathrm{RA}, \mathrm{SC}$, and $\mathrm{EF}$ in correlation to $\mathrm{VC}$ and $\mathrm{D}_{\mathrm{LCO}}$.

\section{Comparison of the lung function parameters VC, $D_{L C O}$} and $D_{L C O} / V A$ with the presence of pleural plaques in $C T$ Patients with pleural plaques $(n=27)$ and a score of at least 1 in the evaluation of plaque distribution in the ICOERD coding scheme (score $A$ ) have a slightly lower vital capacity (VC) compared to patients without pleural plaques $(\rho=-$ 0.19 , n.s.) (Table 3). Likewise, the mean values of the $\mathrm{VC}$ in the separate evaluation of both groups indicate that patients of the collective without pleural plaques in CT show a higher $\mathrm{VC}$ on average than patients with pleural plaques (100.1 and $94.6 \%$, respectively; Table 3 ). The sensitivity of the $\mathrm{VC}$ is correspondingly low in the study group, only 4 of $27(15 \%)$ patients with one or more pleural plaques have pathological VC value (NPV 38\%; Table 4). In contrast, all patients with a significant reduction of $\mathrm{VC}(<\mathrm{LLN})$ also have pleural plaques in CT findings (PPV 100\%). The Shapiro-Wilk test shows a normal distribution for VC as well as for $\mathrm{D}_{\mathrm{LCO}}$ and $\mathrm{D}_{\mathrm{LCO}} / \mathrm{VA}$ (Table 3 ).

Considering the correlation between the score value for pleural plaques and the evidence of a pathological $\mathrm{CO}$ diffusion capacity, similar to the result for $\mathrm{VC}$, only a weak negative correlation is found ( $\rho=-0.19$, n.s.; Table 3).

In the four-field matrix, the $\mathrm{D}_{\mathrm{LCO}}$ of patients without plaques is on average $79.7 \%$, i.e. already in the lower limit range of the predicted values and lower than the VC (Table 3). In the individual analysis, however, only 3 out of 14 , i.e. $21 \%$ of these patients without plaques, show a reduction in $\mathrm{D}_{\mathrm{LCO}}$ below LLN, whereas $44 \%$ (12 out of 27) of patients with at least one pleural plaque show $\mathrm{D}_{\mathrm{LCO}}$ below LLN (Table 4). With 56.1\% accuracy, the $\mathrm{D}_{\mathrm{LCO}}$ thus gives a better indication of the presence of pleural plaques than the vital capacity (accuracy 43.9\%). Thus the $\mathrm{D}_{\mathrm{LCO}}$ shows a positive predictive value of $80 \%$ (specificity $79 \%$, sensitivity 44\%). Cohens Kappa just indicated a slight correlation of the expected with the observed accuracy for $\mathrm{VC}$; for the $\mathrm{D}_{\mathrm{LCO}}$ a nearly sufficient correlation is shown (0.10 and 0.19 resp.; according to [32]).

The transfer coefficient $\mathrm{D}_{\mathrm{LCO}} / \mathrm{VA}$ shows a pathological value in only four patients; the accuracy for the presence of pleural plaques is low with $29.3 \%$ (Table 4). The mean values of this measurement are close to the predicted value in all subgroups; asbestos-related lung and pleural changes do not lead to a reduction of $\mathrm{D}_{\mathrm{LCO}} / \mathrm{VA}$ in this collective, the correlation between pleural plaques and $\mathrm{D}_{\mathrm{LCO}} / \mathrm{VA}$ is poor (Cohens Kappa - 0.13) (Tables 3 and 4). 


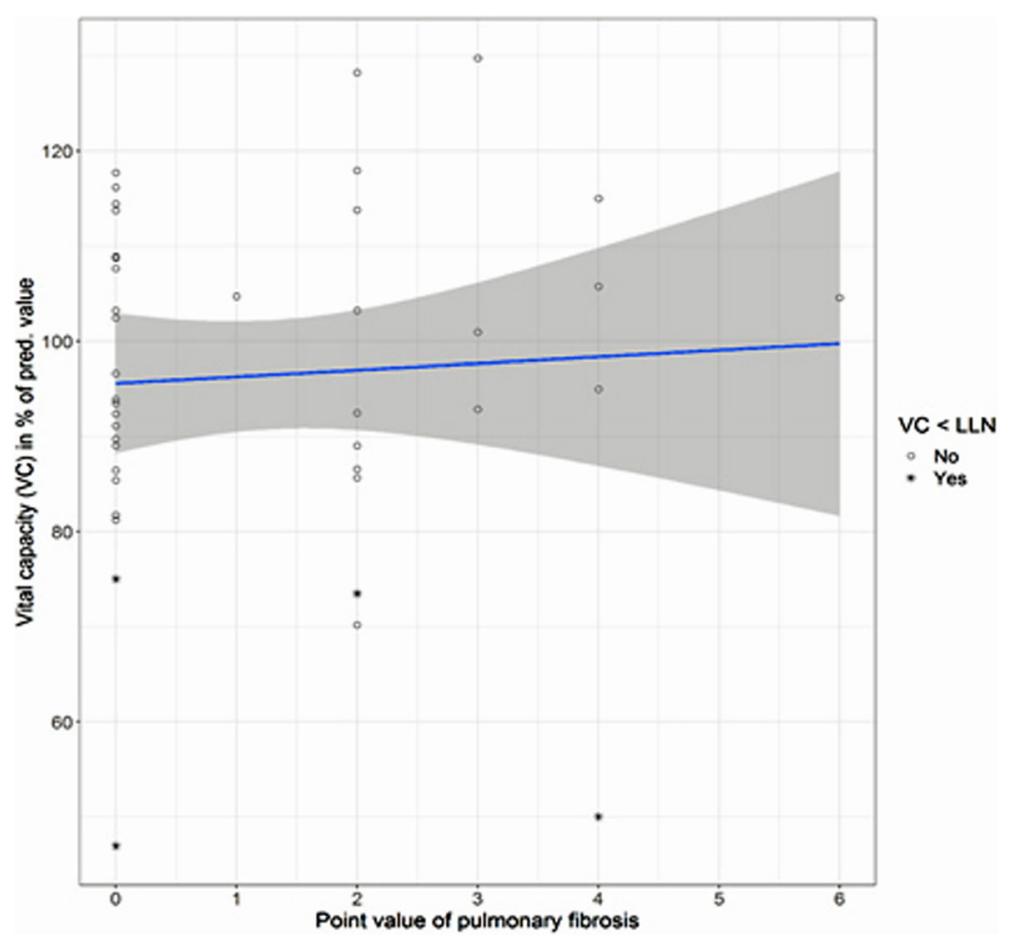

Fig. 2 Comparison of VC with the score $B$ of pulmonary fibrosis according to ICOERD coding scheme $(n=41) . \rho=0.10 ; n$.s. The pathological values of the VC (< lower limit of normal (LLN)) are marked with *

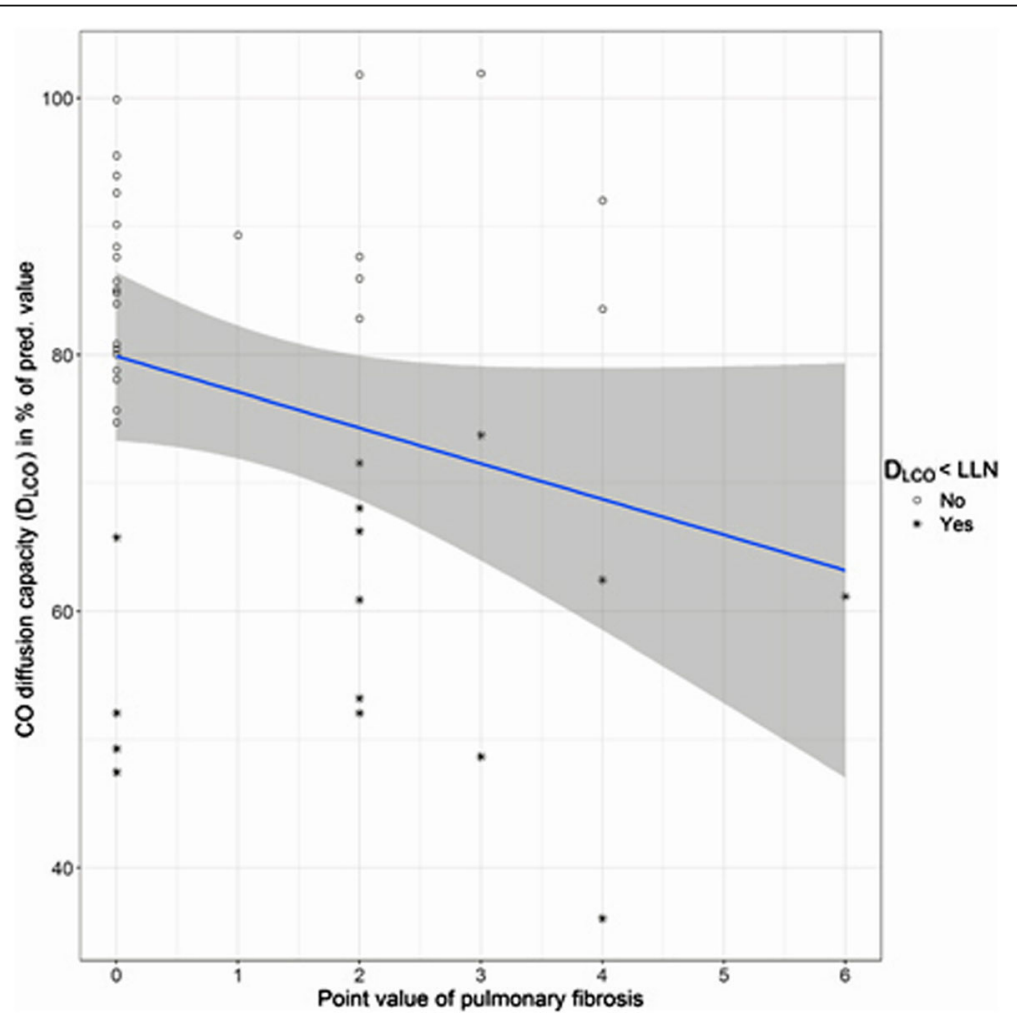

Fig. 3 Comparison of diffusion capacity with the score B of pulmonary fibrosis according to ICOERD coding scheme $(n=41) . \rho=-0.22 ; n . s$. The pathological values of the $D_{L C O}(<$ lower limit of normal (LLN)) are marked with * 


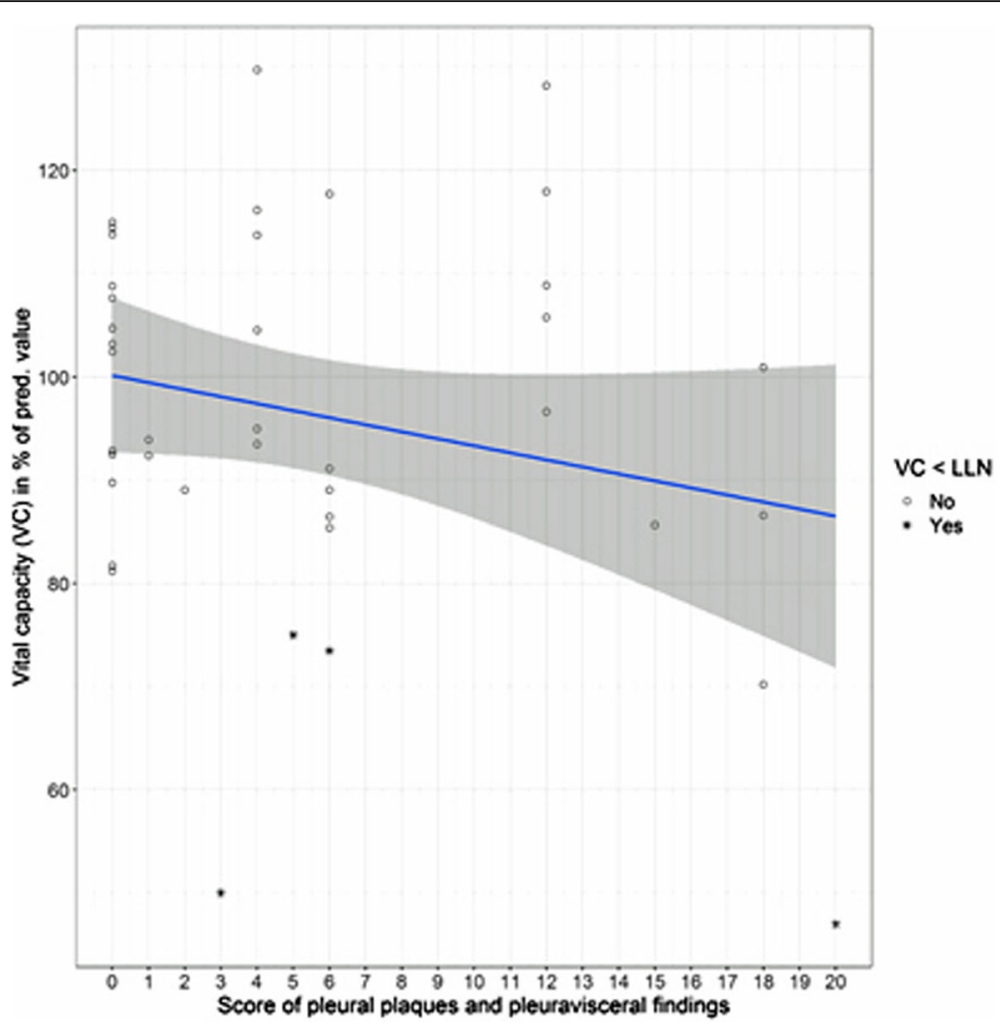

Fig. 4 Comparison of vital capacity with the combined score taking into account parietal and visceral pleural alterations $(n=41)$. $\rho=-0.18$; n.s. The pathological values of the VC $(<$ lower limit of normal (LLN)) are marked with *

\section{Comparison of lung function parameters VC, $\mathrm{D}_{\mathrm{LCO}}$ and $D_{\mathrm{LCO}} / \mathrm{VA}$ with the detection of pulmonary fibrosis}

Pulmonary, i.e. parenchymal, fibrosis is present if at least 2 fields have been marked in the ICOERD coding scheme [5], corresponding to a score $B \geq 2$; higher values indicate a greater extent of pulmonary fibrosis. As mentioned above, 18 patients show pulmonary fibrosis with a score $B$ of 1-6 (of max. 18) points. The vital capacity shows no and the $\mathrm{D}_{\mathrm{LCO}}$ a moderate correlation to the extent of pulmonary fibrosis $(\rho=0.10$ and 0.22, resp., n.s.; Table 3). The relation between the score, i.e. the extent of pulmonary fibrosis, and the pulmonary function parameters $\mathrm{VC}$ and $\mathrm{D}_{\mathrm{LCO}}$ are visualized in Figs 2 and 3.

In patients with pulmonary fibrosis and pathological lung function values, the $\mathrm{D}_{\mathrm{LCO}}$ shows the highest accuracy with $73.2 \%$, followed by the VC with an accuracy of $56.1 \%$ (see four-field matrix, Table 4). Cohens Kappa of 0.45 shows moderate correlation between $\mathrm{D}_{\mathrm{LCO}}$ and pulmonary fibrosis. Once again, $\mathrm{D}_{\mathrm{LCO}} / \mathrm{VA}$ shows no association to the radiological findings with regard to pulmonary fibrosis (Tables 3 and 4).

\section{Comparison of lung function parameters VC, $\mathrm{D}_{\mathrm{LCO}}$ and $D_{\mathrm{LCO}} / \mathrm{VA}$ with the score of parietal pleural changes and diffuse pleural thickening}

This newly developed score considers the local extent of pleural plaques and visceral and subpleural asbestos- related alterations corresponding to the presence of $\mathrm{PB}$, $\mathrm{RA}, \mathrm{SC}$ and EF as described above. The score values range between 0 and 20. For the vital capacity at least a weak correlation with this score is apparent; the $\mathrm{D}_{\mathrm{LCO}}$ shows a mean significant correlation with the score $(\rho=-0.35, p<$ 0.05 ; Table 3). These correlations of lung function parameters and scores are illustrated in Figs 4 and 5 . The $\mathrm{D}_{\mathrm{LCO}} /$ VA shows no correlation to this score (Table 3). The fourfield matrix is not suitable for this score; it would show the same results as for the presence of pleural plaques.

In addition, we have calculated a further score from the addition of the combined score (pleural changes with visceral changes) with the score $B$ for the extent of pulmonary fibrosis. This allows both pleural changes and lung changes caused by asbestos to be adequately considered. The comparison of this score with the $\mathrm{D}_{\mathrm{LCO}}$ showed the highest correlation $(\rho=-0.41 ; p<0.01)$ and the VC shows only a weak correlation $(\rho=-0.12$; n.s. (Data are not shown in figures).

\section{Discussion}

Lung function testing is a simple, non-invasive and inexpensive diagnostic method for early detection and verification of a disease or its progression, thus enabling early intervention. TCT classified by ICOERD shows the extent of asbestos-related morphological changes, but not 


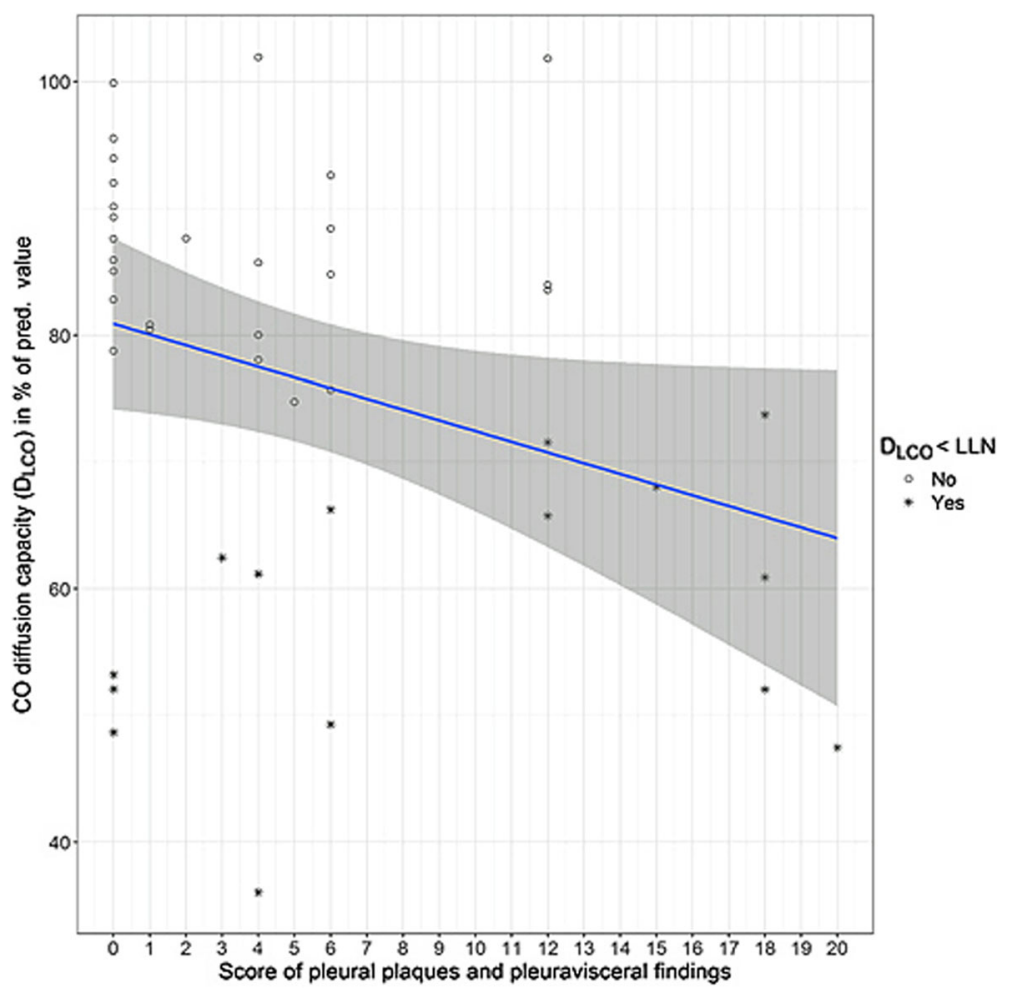

Fig. 5 Comparison of diffusion capacity with the combined score taking into account parietal and visceral pleural alterations $(n=41)$. $\rho=-0.35$; $p=0.03$. The pathological values of the $D_{\mathrm{LCO}}(<$ lower limit of normal $(L L N))$ are marked with *

the effects on volume and gas exchange in the lungs. The aim of this study was to determine whether the results of pulmonary function tests (spirometry and $\mathrm{D}_{\mathrm{LCO}}$ ) can increase the predictive value for the presence of asbestos-related fibrosis.
The classification of the visceral type of asbestosrelated pleural fibrosis with the ICOERD coding scheme [29] requires the specification of at least one finding in the category "symbols" listing intrapulmonary changes like 'parenchymal bands' (PB) and 'round atelectases'

Table 3 Comparison of vital capacity $(V C)$, diffusion capacity $\left(D_{L C O}\right)$, and transfer coefficient $\left(D_{L C O} N A\right)$ of subjects without and with pleural plaques or without and with pulmonary fibrosis in TCT

\begin{tabular}{|c|c|c|c|c|c|c|c|c|}
\hline \multirow[t]{3}{*}{ Shapiro-Wilk-Test } & & \multirow[b]{3}{*}{$\mathbf{n}$} & \multirow{2}{*}{\multicolumn{2}{|c|}{$\begin{array}{l}\text { VC [\% pred.] } \\
p=0.15\end{array}$}} & \multirow{2}{*}{\multicolumn{2}{|c|}{$\begin{array}{l}\text { D Lco [\% pred.] } \\
p=0.06\end{array}$}} & \multirow{2}{*}{\multicolumn{2}{|c|}{$\frac{\text { D Lco } / \text { A [\% pred.] }}{p=0.40}$}} \\
\hline & & & & & & & & \\
\hline & & & Mean & SD & Mean & SD & Mean & SD \\
\hline \multirow[t]{2}{*}{ Pleural plaques } & none & 14 & 100.1 & 11.6 & 79.7 & 16.1 & 98.0 & 23.1 \\
\hline & yes & 27 & 94.6 & 20.5 & 74.6 & 16.8 & 104.5 & 21.3 \\
\hline \multirow{3}{*}{\multicolumn{2}{|c|}{ correlation $\rho$ of pleural plaques (score $A$ ) with lung function parameters }} & & \multicolumn{2}{|c|}{-0.12} & \multicolumn{2}{|c|}{-0.25} & \multicolumn{2}{|c|}{0.12} \\
\hline & & \multirow[t]{2}{*}{$\mathbf{n}$} & \multicolumn{2}{|c|}{ VC $[\%$ pred.] } & \multicolumn{2}{|c|}{$\mathbf{D}_{\text {Lco }}[\%$ pred.] } & \multicolumn{2}{|c|}{$\mathbf{D}_{\text {Lco }} /$ VA [\% pred.] } \\
\hline & & & Mean & SD & Mean & SD & Mean & SD \\
\hline \multirow[t]{2}{*}{ Pulmonary fibrosis } & none & 23 & 95.7 & 16.2 & 80.0 & 14.2 & 106.2 & 20.6 \\
\hline & yes & 18 & 97.5 & 20.4 & 61.3 & 18.0 & 97.3 & 23.6 \\
\hline \multicolumn{3}{|c|}{ correlation $\rho$ of pulmonary fibrosis (score $B$ ) with lung function parameters } & \multicolumn{2}{|c|}{0.10} & \multicolumn{2}{|c|}{-0.22} & \multicolumn{2}{|c|}{-0.26} \\
\hline \multicolumn{9}{|l|}{ Combined score } \\
\hline \multicolumn{2}{|c|}{$\begin{array}{l}\text { correlation } \rho \text { of the combined score of parietal pleural changes and diffuse } \\
\text { pleural thickening with lung function parameters }\end{array}$} & & \multicolumn{2}{|c|}{-0.18} & \multicolumn{2}{|c|}{$-0.35^{*}$} & \multicolumn{2}{|c|}{0.09} \\
\hline
\end{tabular}

$\rho$ correlation (Spearmans rho, LLN lower limit of normal; ${ }^{*}$ significant $(p<0.05)$ 
Table 4 Four-field matrixes for comparison of lung function parameters with findings of pleural plaque resp. of pulmonary fibrosis $^{b}$

\begin{tabular}{|c|c|c|c|c|c|c|c|}
\hline \multirow[t]{2}{*}{$C T$} & & \multicolumn{2}{|l|}{ VC } & \multicolumn{2}{|l|}{$D_{\text {LCO }}$} & \multicolumn{2}{|c|}{$D_{\text {Lco }} /$ A } \\
\hline & & $\geq \operatorname{LLN}$ & $<\mathrm{LLN}$ & $\geq \operatorname{LLN}$ & $<\mathrm{LLN}$ & $\geq \operatorname{LLN}$ & $<\mathrm{LLN}$ \\
\hline \multirow[t]{2}{*}{ Pleural plaques } & none & 14 & 0 & 11 & 3 & 11 & 3 \\
\hline & yes & 23 & 4 & 15 & 12 & 26 & 1 \\
\hline Accuracy & & \multicolumn{2}{|c|}{$43.9 \%$} & \multicolumn{2}{|c|}{$56.1 \%$} & \multicolumn{2}{|c|}{$29.3 \%$} \\
\hline Cohens Kappa & & \multicolumn{2}{|c|}{0.10} & \multicolumn{2}{|c|}{0.19} & \multicolumn{2}{|c|}{-0.13} \\
\hline \multirow[t]{2}{*}{ Pulmonary fibrosis } & none & 21 & 2 & 19 & 4 & 22 & 1 \\
\hline & yes & 16 & 2 & 7 & 11 & 15 & 3 \\
\hline Accuracy & & \multicolumn{2}{|c|}{$56.1 \%$} & \multicolumn{2}{|c|}{$73.2 \%$} & \multicolumn{2}{|c|}{$61.0 \%$} \\
\hline Cohens Kappa & & \multicolumn{2}{|c|}{0.03} & \multicolumn{2}{|c|}{0.45} & \multicolumn{2}{|c|}{0.13} \\
\hline
\end{tabular}

apleural plaque means $\geq 1 \mathrm{P}$. in score $A ;{ }^{b}$ pulmonary fibrosis means $\geq 2 \mathrm{P}$. in score $B ; V C$ vital capacity, $L L N$ lower limit of normal, $D_{L C O}$ diffusion capacity with $C O$ $D_{L C O}$ VA diffusion capacity with $\mathrm{CO}$ in relation to alveolar volume

(RA). Diagnostic findings as 'subpleural curvilinear lines' (SC) and 'effusion, free or loculated pleural fluid' (EF) are associated with previous exposures to asbestos and have therefore been included in our newly developed scoring system.

According to our pathophysiological model, besides $\mathrm{PB}, \mathrm{RA}, \mathrm{SC}$, and $\mathrm{EF}$, other diagnostic findings listed in the ICOERD coding scheme could also affect the functionality of the lung, such as calcification of the plaques. For this purpose, the combined score included these diagnostic findings and was applied within the study collective. The consideration of PB and RA additionally to the pleural plaque values, but without the scores for $\mathrm{SC}$ and EF was also tested. By including PB, RA, SC, and EF in addition to the extent of pleural plaques in the statistical model, significant changes in lung function could be demonstrated.

Compared to spirometry with VC determination, our study showed $\mathrm{D}_{\mathrm{LCO}}$ to be the more sensitive diagnostic method with better accuracy for detecting asbestosrelated changes in the lung and pleura. With the high positive predictive value of $80 \%$ and a specificity of $79 \%$ reduction of the $\mathrm{D}_{\mathrm{LCO}}$ is strongly associated with radiological findings $(\mathrm{CT})$ of asbestosis.

Vital capacity also showed a negative correlation, when the pleural plaques were taken into account. In our statistical analysis there was no dependence of $\mathrm{VC}$ on the severity of fibrotic parenchymal changes. This might be attributed to the moderate fibrosis (maximum score was 6 of theoretically achievable 18 points) in all cases. Likewise, Sener et al. [33] described only a weak negative correlation between $\mathrm{FEV}_{1}$ and FVC decrease with the increase of small opacitiy grades in HRCT; however, the $\mathrm{D}_{\mathrm{LCO}}$ was not investigated by these authors. Barnikel et al. [34] showed a decrease of FVC and $\mathrm{D}_{\mathrm{LCO}}$ in 56 asbestos exposed subjects, particularly significant in cases with fibrotic phenotype in HRCT. The present study confirms the results of Park et al. [15] and Miles et al. [35] who described the decrease of $\mathrm{D}_{\mathrm{LCO}}$ in the presence of asbestos-related changes depending on the extent of pleural plaques, diffuse pleural thickening and asbestosis. In addition, Cha et al. [16] found a decrease in $D_{\mathrm{LCO}}$ in the presence of manifest asbestos-related pleural plaques although not statistically significant; however, this study did not consider additional abnormalities like PB or SC in their analyses.

In the present study, $\mathrm{D}_{\mathrm{LCO}} / \mathrm{VA}$ was not sensitive, confirming the results of van der Lee et al. [36] and Hughes \& Pride [37] where the transmission coefficient $\mathrm{D}_{\mathrm{LCO}} /$ VA had no diagnostic added value compared to the parameters $\mathrm{D}_{\mathrm{LCO}}$ and $\mathrm{VC}$ for the detection of diffuse parenchymal diseases. In accordance, Schikowsky et al. [38] showed no impairment of $\mathrm{D}_{\mathrm{LCO}} / \mathrm{VA}$ and no reduction in $\mathrm{VC}$ in subjects formerly exposed to asbestos. In difference, the $D_{\mathrm{LCO}}$ results were not presented.

One of the strengths of the present study is the limitation to study participants without confounding factors. This applies in particular to the exclusion of patients with heart disease and emphysema, as the latter can be caused by inhalation of mineral dusts, but also by smoking. Both diseases can significantly impair the results of lung function, especially the $\mathrm{D}_{\mathrm{LCO}}$. The results can be regarded as specific for the changes caused by asbestos.

We can show no dependency between lung function and the dose of previous exposure to asbestos. This may be due to inaccuracies in the recording of these events, which date back decades. Often, only rough dose-effect relationships are described for the development of asbestos-related changes [39]. All study participants provided explicit proof of occupational exposure to asbestos; therefore all were diagnosed with asbestosis, not as interstitial pneumonia or idiopathic pulmonary fibrosis, as even the small amounts can lead to the occurrence of asbestosis $[8,39,40]$.

\section{Limitations}

Because the patient data were collected over a period of 4 years, a particular challenge arose from the fact that 
different CT scanners had been used, which had to meet certain quality criteria depending on the $\mathrm{CT}$ scanner. After careful review, data sets that did not meet the defined CT quality criteria had to be removed from the study [8].

Exposure to asbestos fibre dust in combination with smoking has significant effects on the findings both in TCT and in lung function tests [41]. Especially in heavy smokers, these findings can be difficult to distinguish from patients with mild asbestosis. However, these were only a few subjects (Table 1) and we did not analyse them separately.

The assessment of the TCT after ICOERD was performed by radiologists familiar with pneumoconiosis; however, no controls could be performed by a second radiologist. Minor inaccuracies in the calculated scores could therefore occur, even if the interreader variability in the findings with the ICOERD is low, as Suganuma et al. [30] showed.

TCT and pulmonary function were usually not performed on the same day, in some cases the tests were several months apart. This had to be accepted due to the very slow progression of asbestos-related fibrosis, as conducting such a study does not allow an indication for further radiation exposure to TCT.

\section{Conclusions}

The correlation of lung function changes and TCT findings was strongest when $\mathrm{D}_{\mathrm{LCO}}$ was used and ICOERD classification of TCT included parenchymal bands, subpleural curvilinear lines, round atelectasis, and pleural effusion in addition to pleural plaque extension. In correlation to the exclusively pulmonary findings, $\mathrm{D}_{\mathrm{LCO}}$ showed the highest accuracy, but VC only a weaker correlation. Therefore, lung function parameter $\mathrm{D}_{\mathrm{LCO}}$ should be included as complementary parameter to VC in future examinations for the detection of asbestosis. In the evaluation of radiological imaging of morphological asbestos-related lung and pleural changes, the presence of parenchymal bands, subpleural curvilinear lines, round atelectasis and pleural effusion are predictive for pulmonary insufficiency and might also be included in the evaluation of ICOERD-findings.

\footnotetext{
Abbreviations

\%pred.: Percent of predicted value; ANOVA: Analysis of variance; ATS: American Thoracic Society; BMI: Body Mass Index; CO: Carbon monoxide; Cohens K: Cohen's kappa coefficient; $\mathrm{D}_{\mathrm{LCO}}$ : CO diffusion capacity;

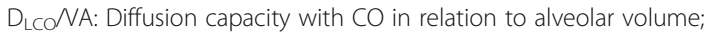
ECSC: European Coal and Steel Community; EF: Effusion, free or loculated pleural fluid; ERS: European Respiratory Society; FEV ${ }_{1}$ : Forced expiratory vital capacity over one second; FEV 1 /FVC: Lung volumes at normal relative onesecond capacity; FVC: Forced expiratory vital capacity; GLI: Global Lung Initiative; Hb: Haemoglobin content of the blood; HRCT: High-resolution computed tomography; ICOERD: Computed Tomography for Occupational and Environmental Respiratory Diseases; L: Left; L: Lower field; LLN: Lower limit of normal; M: Middle field; Mean: Average (mean) value in a sample; Median: Median value of a range of values; $\mathrm{n}$ : Number (of subjects included); n.s.: Not significant; $p$ : Probability value; PB: Parenchymal bands; py: Pack
}

years; R: Right; RA: Round atelectasis; resp.: Respective; RV: Residual volume; RV/TLC: Share of residual volume in total lung capacity; SB: Single breath; SC: Subpleural curvilinear lines; SD: Standard deviation; sR: Specific resistance; TCT: Computed tomography of the thorax; TLC: Total lung capacity; U: Upper field; ULN: Upper limit of normal; VC: Vital capacity; VC max: Largest measured vital capacity; VIN: Inspiratory volume; $\rho$ : Spearman's rank correlation coefficient (Spearman's rho)

\section{Acknowledgments \\ The authors would like to thank Sabine Bößler and Anne Winkelmann for their careful conduct of the lung function tests and Dr. Eva Hampel for her support in writing the English manuscript.}

\section{Authors' contributions}

AMP conceived the study hypothesis, conducted the data extraction, participated in the analysis of the results, interpreted the results, and drafted the manuscript. KS extracted the relevant data for analysis, and participated in the analysis and interpretation of the results. $\mathrm{RH}$ performed the statistical analyses. AL evaluated the radiological method and data. CT supported the analysing and interpretation of the results and paper editing. $\mathrm{VH}$ supervised the interpretation of results and paper editing. All the authors read and approved the final manuscript.

\section{Funding}

None.

\section{Availability of data and materials \\ Not applicable.}

Ethics approval and consent to participate Not applicable.

\section{Consent for publication}

Consent for the replication of figures previously published in other publications exists (the authors own the copyright).

\section{Competing interests}

The authors report no conflicts of interest in this work.

\section{Author details}

${ }^{1}$ Institute for Occupational and Maritime Medicine (ZfAM), University Medical Center Hamburg-Eppendorf (UKE), Hamburg, Germany. ${ }^{2}$ Department of Diagnostic and Interventional Radiology and Nuclear Medicine, University Medical Center Hamburg-Eppendorf (UKE), Hamburg, Germany.

Received: 3 January 2020 Accepted: 21 June 2020

Published online: 01 July 2020

\section{References}

1. Deutsche Gesetzliche Unfallversicherung (DGUV). BK-Verdacht bestätigt https://www.dguv.de/de/zahlen-fakten/bk-geschehen/bestaetigte-bk-faelle/ index.jsp. Accessed 13 Dec 2019.

2. Deutsche Gesetzliche Unfallversicherung (DGUV). Todesfälle infolge einer Berufskrankheit. https://www.dguv.de/de/zahlen-fakten/bk-geschehen/bktodesfaelle/index.jsp. Accessed 13 Dec 2019

3. Deutsche Gesetzliche Unfallversicherung (DGUV). Geschäfts- und Rechnungsergebnisse 2017 der gewerblichen Berufsgenossenschaften und Unfallversicherungsträger der öffentlichen Hand. https://publikationen.dguv. de/widgets/pdf/download/article/3458. Accessed 12 Dec 2019

4. Eisenhawer C, Felten MK, Tamm M, Das M, Kraus T. Radiological surveillance of formerly asbestos-exposed power industry workers: rates and risk factors of benign changes on chest X-ray and MDCT. J Occup Med Toxicol. 2014;9: 18. https://doi.org/10.1186/1745-6673-9-18.

5. Hieckel HG, Hering KG. Asbestverursachte Veränderungen am thorax. [Asbestos-related diseases of the thorax]. Radiologe. 2010;50(7):623-33quiz 634. https://doi.org/10.1007/s00117-010-2015-8.

6. Hering KG, Hofmann-Preiß K. Pneumokoniosen erkennen und klassifizieren. [recognize and classify pneumoconiosis]. Radiologe. 2014;54(12):1189-98. https://doi.org/10.1007/s00117-014-2735-2.

7. Jakobsson K, Strömberg U, Albin M, Welinder H, Hagmar L. Radiological changes in asbestos cement workers. Occup Environ Med. 1995;52(1):20-7. 
8. Hering KG, Hofmann-Preiß K, Kraus T. Update: Standardisierte $C T-/ H R C T$ Klassifikation der Bundesrepublik Deutschland für arbeits- und umweltbedingte Thoraxerkrankungen. [update: standardized CT/HRCT classification of occupational and environmental thoracic diseases in Germany]. Radiologe. 2014;54(4):363-84. https://doi.org/10.1007/s00117-014-2674-y.

9. Paris C, Benichou J, Raffaelli C, Genevois A, Fournier L, Menard G, et al. Factors associated with early-stage pulmonary fibrosis as determined by high-resolution computed tomography among persons occupationally exposed to asbestos. Scand J Work Environ Health. 2004;30(3):206-14. https://doi.org/10.5271/sjweh.781.

10. Wolff $\mathrm{H}$, Vehmas $\mathrm{T}, \mathrm{Oksa} P$, Rantanen J, Vainio H. Asbestos, asbestosis, and cancer, the Helsinki criteria for diagnosis and attribution 2014: recommendations. Scand J Work Environ Health. 2015;41(1):5-15. https:// doi.org/10.5271/sjweh.3462.

11. Wilken D, Velasco Garrido M, Manuwald U, Baur X. Lung function in asbestos-exposed workers, a systematic review and meta-analysis. J Occup Med Toxicol. 2011;6:21. https://doi.org/10.1186/1745-6673-6-21.

12. Miller A, Warshaw R, Nezamis J. Diffusing capacity and forced vital capacity in 5,003 asbestos-exposed workers: relationships to interstitial fibrosis (ILO profusion score) and pleural thickening. Am J Ind Med. 2013;56(12):1383-93. https://doi.org/10.1002/ajim.22239.

13. Kopylev L, Christensen KY, Brown JW, Cooper GS. Authors' response: a systematic review of the association between pleural plaques and changes in lung function. Occup Environ Med. 2015;72(9):685-6. https://doi.org/10. 1136/oemed-2015-103063.

14. Abejie BA, Wang $X$, Kales SN, Christiani DC. Patterns of pulmonary dysfunction in asbestos workers: a cross-sectional study. J Occup Med Toxicol. 2010;5:12. https://doi.org/10.1186/1745-6673-5-12.

15. Park EK, Yates DH, Wilson D. Lung function profiles among individuals with nonmalignant Asbestos-related disorders. Saf Health Work. 2014;5(4):234-7. https://doi.org/10.1016/j.shaw.2014.07.007.

16. Cha YK, Kim JS, Kwon JH. Quantification of pleural plaques by computed tomography and correlations with pulmonary function: preliminary study. J Thorac Dis. 2018;10(4):2118-24. https://doi.org/10.21037/jtd.2018.04.02.

17. Preisser AM, Velasco Garrido M, Goldenstein ES, Schumann G, Manuwald U, Wilken $\mathrm{D}$, et al. CO-diffusion capacity in asbestos-exposed workers with or without abnormal chest X-ray findings. Eur Respir J. 2011;38(Suppl 55):p1053.

18. Vogelmeier C, Buhl R, Burghuber O, Criée CP, Ewig S, Godnic-Cvar J, et al. S2k-Leitlinie zur Diagnostik und Therapie von Patienten mir chronisch obstruktiver Bronchitis und Lungenemphysem (COPD). https://www.awmf. org/uploads/tx_szleitlinien/020-006l_S2K_COPD_chronisch-obstruktiveLungenerkrankung_2018-01.pdf. Accessed 12 Dec 2019.

19. Ulmer WT, Nolte D, Lecheler J, Schäfer T. Die Lungenfunktion. Methodik und klinische Anwendung. 7th ed. Stuttgart, New York: Georg Thieme Verlag; 2003. https://doi.org/10.1055/b-002-44941.

20. Miller MR, Hankinson J, Brusasco V, Burgos F, Casaburi R, Coates A, et al. Standardisation of spirometry. Eur Respir J. 2005;26(2):319-38. https://doi. org/10.1183/09031936.05.00034805.

21. Pellegrino R, Viegi G, Brusasco V, Crapo RO, Burgos F, Casaburi R, et al. Interpretative strategies for lung function tests. Eur Respir J. 2005;26(5):94868. https://doi.org/10.1183/09031936.05.00035205.

22. Criée CP, Baur X, Berdel D, Bösch D, Gappa M, Haidl P, et al. Leitlinie zur Spirometrie: Leitlinie der Deutschen Atemwegsliga der Deutschen Gesellschaft für Pneumologie und Beatmungsmedizin und der Deutschen Gesellschaft für Arbeitsmedizin und Umweltmedizin zur Spirometrie. [standardization of spirometry: 2015 update. Published by German Atemwegsliga, German respiratory society and German Society of Occupational and Environmental Medicine]. Pneumologie. 2015;69(3):14764. https://doi.org/10.1055/s-0034-1391345.

23. Quanjer PH, Stanojevic S, Cole TJ, Baur X, Hall GL, Culver BH, et al. Multiethnic reference values for spirometry for the 3-95 year age range: the global lung function 2012 equations. Eur Respir J. 2012;40(6):1324-43. https://doi.org/10.1183/09031936.00080312.

24. Quanjer PH, Tammeling GJ, Cotes JE, Pedersen OF, Peslin R, Yernault JC. Lung volumes and forced ventilatory flows. Eur Respir J. 1993;6(Suppl 16):540. https://doi.org/10.1183/09041950.005s1693.

25. Maclntyre N, Crapo RO, Viegi G, Johnson DC, van der Grinten CP, Brusasco $V$, et al. Standardisation of the single-breath determination of carbon monoxide uptake in the lung. Eur Respir J. 2005;26(4):720-35. https://doi. org/10.1183/09031936.05.00034905.

26. Graham BL, Brusasco V, Burgos F, Cooper BG, Jensen R, Kendrick A, et al. ERS/ATS standards for single-breath carbon monoxide uptake in the lung.
Eur Respir J. 2017;49(1):1600016. https://doi.org/10.1183/13993003.000162016.

27. Cotes JE, Chinn DJ, Quanjer PH, Roca J, Yernault JC. Standardization of the measurement of transfer factor (diffusing capacity). Eur Respir J. 1993: 6(Suppl 16):41-52. https://doi.org/10.1183/09041950.041s1693.

28. Mottram C, Blonshine S, Brown RA, Ruppel GL, Wanger J. AARC clinical practice guideline. Single-breath carbon monoxide diffusing capacity; 1999. Update. http://www.rcjournal.com/cpgs/sbcmdc99cpg.html. Accessed 12 Dec 2019.

29. Hering K, Kraus T. Coding CT-classification in occupational and environmental respiratory disease (OERD). In: Kusaka Y, Hering K, Parker J, editors. International classification of HRCT for occupational and environmental respiratory diseases. Tokyo: Springer; 2005. p. 15-23. https:// doi.org/10.1007/4-431-27512-6_3. http://extras.springer.com/2005/ 978-4-431-23924-6/2_Reading\%20Sheet.pdf. Accessed 12 Dec 2019.

30. Suganuma N, Kusaka Y, Hering KG, Vehmas T, Kraus T, Arakawa H, et al. Reliability of the proposed international classification of high-resolution computed tomography for occupational and environmental respiratory diseases. J Occup Health. 2009;51(3):210-22. https://doi.org/10.1539/joh.18030.

31. Vainio H, Oksa P, Tuomi T, Vehmas T, Wolff H. Helsinki criteria update 2014: asbestos continues to be a challenge for disease prevention and attribution. Epidemiol Prev. 2016;40(1 Suppl 1):15-9. https://doi.org/10.19191/EP16.1S1. P015.025.

32. Landis JR, Koch GG. The measurement of observer agreement for categorical data. Biometrics. 1977;33(1):159-74.

33. Sener MU, Simșek C, Özkara S, Evran H, Bursali I, Gökçek A. Comparison of the international classification of high-resolution computed tomography for occupational and environmental respiratory diseases with the international labor organization international classification of radiographs of pneumoconiosis. Ind Health. 2019;57(4):495-502. https://doi.org/10.2486/ indhealth.2018-0068.

34. Barnikel M, Million PM, Knoop H, Behr J. The natural course of lung function decline in asbestos exposed subjects with pleural plaques and asbestosis. Respir Med. 2019;154:82-5. https://doi.org/10.1016/j.rmed.2019.06.013.

35. Miles SE, Sandrini A, Johnson AR, Yates DH. Cinical consequences of asbestos-related diffuse pleural thickening: a review. J Occup Med Toxicol. 2008:3:20. https://doi.org/10.1186/1745-6673-3-20.

36. van der Lee I, Zanen P, van den Bosch JM, Lammers JW. Pattern of diffusion disturbance related to clinical diagnosis: the $\mathrm{K}(\mathrm{CO})$ has no diagnostic value next to the DL (CO). Respir Med. 2006;100(1):101-9. https://doi.org/10.1016/j. rmed.2005.04.014

37. Hughes JM, Pride NB. Examination of the carbon monoxide diffusing capacity (DL (CO)) in relation to its KCO and VA components. Am J Respir Crit Care Med. 2012;186(2):132-9. https://doi.org/10.1164/rccm.201112-2160Cl.

38. Schikowsky C, Felten MK, Eisenhawer C, Das M, Kraus T. Lung function not affected by asbestos exposure in workers with normal computed tomography scan. Am J Ind Med. 2017;60(5):422-31. https://doi.org/10.1002/ ajim.22717.

39. Baur X, Clasen M, Fisseler-Eckhoff A, Heger M, Hering KG, Hofmann-Preiss K, et al. Diagnostik und Begutachtung asbestbedingter Berufskrankheiten. Interdisziplinäre S2-Leitlinie der Deutschen Gesellschaft für Pneumologie und Beatmungsmedizin und der Deutschen Gesellschaft für Arbeitsmedizin und Umweltmedizin. [diagnostics and expert opinion of asbestos-induced occupational diseases. Interdisciplinary guideline of the German respiratory society and the German Society of Occupational and Environmental Medicine]. Pneumologie. 2011;65(3):e1-47. https://doi.org/10.1055/s-00301255992.

40. Raghu G, Collard HR, Egan JJ, Martinez FJ, Behr J, Brown KK, et al. An official ATS/ ERS/ JRS/ ALAT statement: idiopathic pulmonary fibrosis: evidencebased guidelines for diagnosis and management. Am J Respir Crit Care Med. 2011;183(6):788-824. https://doi.org/10.1164/rccm.2009-040GL.

41. Bledsoe J, Christiani DC, Kradin RL. Smoking-associated fibrosis and pulmonary asbestosis. Int J Chron Obstruct Pulmon Dis. 2014;10:31-7. https://doi.org/10.2147/COPD.S74643.

\section{Publisher's Note}

Springer Nature remains neutral with regard to jurisdictional claims in published maps and institutional affiliations. 